\title{
Analysis of Lard in Lipstick Formulation Using FTIR Spectroscopy and Multivariate Calibration: A Comparison of Three Extraction Methods
}

\author{
Dri Waskitho ${ }^{1,2}$, Endang Lukitaningsih ${ }^{1,3}$, Sudjadi $^{1}$ and Abdul Rohman ${ }^{1,3 *}$ \\ ${ }^{1}$ Faculty of Pharmacy, Gadjah Mada University, Yogyakarta 55281, INDONESIA \\ ${ }^{2}$ The National Agency of Drug and Food Control, District of Bali, Central Kalimantan, INDONESIA \\ ${ }^{3}$ Research Center of Halal Products, Gadjah Mada University, Yogyakarta 55281, INDONESIA
}

\begin{abstract}
Analysis of lard extracted from lipstick formulation containing castor oil has been performed using FTIR spectroscopic method combined with multivariate calibration. Three different extraction methods were compared, namely saponification method followed by liquid/liquid extraction with hexane/ dichlorometane/ethanol/water, saponification method followed by liquid/liquid extraction with dichloromethane/ethanol/water, and Bligh \& Dyer method using chloroform/methanol/water as extracting solvent. Qualitative and quantitative analysis of lard were performed using principle component (PCA) and partial least square (PLS) analysis, respectively. The results showed that, in all samples prepared by the three extraction methods, PCA was capable of identifying lard at wavelength region of $1200-800 \mathrm{~cm}^{-1}$ with the best result was obtained by Bligh \& Dyer method. Furthermore, PLS analysis at the same wavelength region used for qualification showed that Bligh and Dyer was the most suitable extraction method with the highest determination coefficient $\left(\mathbf{R}^{2}\right)$ and the lowest root mean square error of calibration (RMSEC) as well as root mean square error of prediction (RMSEP) values.
\end{abstract}

Key words: lipstick, lard, FTIR spectrophotometry, principle component analysis, partial least square

\section{Introduction}

Currently, the use of cosmetics products increases tremendously. Lipstick is one of cosmetics that is widely used by women. It is considered by some women as a necessary additive to their faces in order to feel presentable, comfortable and more confident ${ }^{1)}$. In cosmetics, lard (LD) is usually used as an emulsifying agent, emollient, occlusive and viscosity-increasing agent. In addition, LD and LD-derived ingredients are used in the formulation of skin care products and makeup such as eyebrow pencils, eyeliner and lipstick $^{2)}$. However, the use of lard in cosmetics products is prohibited by certain religion, such as Islam ${ }^{3)}$. Nevertheless, Food and Drug Administration(FDA) has listed LD as one of the generally recognized safe substances ${ }^{4)}$. Therefore, an analytical method offering fast and reliable result is necessary to detect the presence of $\mathrm{LD}$ in cosmetics for halal authentication studies.

The primary components of lipsticks are oils, fats, waxes, and coloring agents. Castor oil is frequently used in the formulation of lipstick because of its high viscosity and good ability to dissolve staining-dye ${ }^{5)}$. For this reason, in this study, castor oil is used as oil mixture with LD in lipstick formulation. Several analytical techniques such as Fourier transform infrared (FTIR) spectroscopy ${ }^{6-8)}$, differential scanning calorimetry, gas chromatography, high performance liquid chromatography ${ }^{9,10)}$, and electronic nose ${ }^{11,12)}$ have been developed for analysis of LD in food and pharmaceutical products. Among those methods, Fourier transform infrared (FTIR) spectroscopy has become a method of choice for analysis of oils and fats because it is fast and non-destructive, sensitive, easy sample handling, and environmentally friendly ${ }^{13)}$.

In cosmetics, FTIR spectroscopic method has been developed for analysis of lard in a mixture with virgin coconut oil in cosmetic cream ${ }^{14)}$ and in a mixture with palm oil in lotion $^{15)}$. However, to the best of our knowledge, the use of FTIR spectroscopic technique combined with certain chemometrics technique for the analysis of lard in lipstick has not been reported. Therefore, the objective of this research was to develop FTIR spectroscopy combined with multi-

\footnotetext{
*Correspondence to: Abdul Rohman, Faculty of Pharmacy, Gadjah Mada University, Yogyakarta 55281, INDONESIA, Research Center of Halal Products, Gadjah Mada University, Yogyakarta 55281, INDONESIA

E-mail: abdul_kimfar@ugm.ac.id or abdulkimfar@gmail.com

Accepted May 16, 2016 (received for review December 21, 2015)

Journal of Oleo Science ISSN 1345-8957 print / ISSN 1347-3352 online

http://www.jstage.jst.go.jp/browse/jos/ http://mc.manusriptcentral.com/jjocs
} 
variate analysis of partial least square(PLS) and principal component analysis (PCA) for the quantification and classification of lard in lipstick formula.

In this study, we also investigated three different extraction methods, i.e. (1) saponification method followed by liquid/liquid extraction with hexane/dichlorometane/ ethanol/water, (2) saponification method followed by liquid/liquid extraction with dichlorometane/ethanol/water, and (3) Bligh and Dyer method using chloroform/methanol/ water as extracting solvent, capable of identifying and quantifying lard extracted from lipstick formulation.

\section{Materials and methods}

\subsection{Preparation of Lard}

Lard (LD) was obtained by rendering adipose tissue of pig purchased from some local markets in Yogyakarta, Indonesia. Adipose tissue was cut into small pieces and melted in a conventional oven and filtered through cotton, dried with anhydrous $\mathrm{Na}_{2} \mathrm{SO}_{4}$, and filtered again through cotton. The filtered fat was stored in tightly closed container in a refrigerator until being used for preparation of lipsticks.

\subsubsection{Preparation of Lipsticks}

For each $100 \mathrm{~g}$, the lipsticks used consisted of LD or castor oil (CT) as well as their blends $(50.0 \mathrm{~g})$, titanium dioxide (6.0 g), red iron oxide ( $1.9 \mathrm{~g})$, Eosin Yellowish $(0.5$ $\mathrm{g})$, isopropyl myristate $(10.0 \mathrm{~g})$, carnauba wax $(9.0 \mathrm{~g})$, bees wax $(13.0 \mathrm{~g})$, lanolin $(4.5 \mathrm{~g})$, cetyl alcohol $(4.5 \mathrm{~g})$, butylated hydroxytoluene $(0.1 \mathrm{~g})$, and rose oil $(0.5 \mathrm{~g})$. To prepare the lipstick formulation, each ingredient was weighted in analytical balance. Pigments, dye, fat and oils were ground together in a mortar until homogenous mixture was obtained (oil phase). Waxy ingredients and antioxidant were melted together by heating at about $70^{\circ} \mathrm{C}$ (wax phase). The oil phase was poured into the wax phase and stirred continuously with a glass rod. Perfume was added to the mixture, and poured into a mould and freezed to obtain a stick form.

\subsection{Calibration and Validation Samples}

For calibration samples, eleven lipstick samples with varied LD concentrations were prepared by laboratoryscale production. The weight percentage ratios of lard and castor oil used were as follows (Table 1).

\subsubsection{Fat/oil Extraction}

We used saponification method I, saponification method II and Bligh and Dyer method during fat/oil extraction from lipstick formulation. Extractions were performed as three replicates.

\subsubsection{Saponification Method I}

To about $4.0 \mathrm{~g}$ of lipstick sample, $30 \mathrm{~mL}$ of $0.2 \mathrm{~N} \mathrm{KOH}$ solution in $90 \% \mathrm{v} / \mathrm{v}$ aqueous ethanol was added and the mixture was refluxed at about $70^{\circ} \mathrm{C}$ for 1.5 hours. After saponification process, the mixture was transferred to a separatory funnel and mixed with $10 \mathrm{~mL}$ of distilled water. Unsaponifiable substances were extracted with $2 \times 15 \mathrm{~mL}$ of $n$-hexane. The hexane phase was discarded and the remaining aquous phase was acidified to $\mathrm{pH} 1$ by addition of $6 \mathrm{~N} \mathrm{HCl}$ solution, and extracted with $2 \times 15 \mathrm{~mL}$ of solvent mixture containing $n$-hexane and dichloromethane $(1: 1, \mathrm{v} /$ v). The aqueous phase was removed and the hexane-dichloromethane extract was combined and dried by adding anhydrous $\mathrm{Na}_{2} \mathrm{SO}_{4}$. After being filtered through Whatmann filter paper, the extract was evaporated using a vacuum rotary evaporator at $40^{\circ} \mathrm{C}$ until solvent was completely removed ${ }^{16)}$. The lipid extracts obtained were further analyzed using FTIR spectrophotometer.

\subsubsection{Saponification Method II}

To about $4.0 \mathrm{~g}$ of lipstick sample, $21 \mathrm{~mL}$ of $0.3 \mathrm{~N} \mathrm{KOH}$ solution in $60 \% \mathrm{v} / \mathrm{v}$ aqueous ethanol was added and the mixture was refluxed at about $70^{\circ} \mathrm{C}$ for 1.5 hour. The saponified mixture was transferred to a separatory funnel after which $10 \mathrm{~mL}$ of distilled water was added. Unsaponifiable substances were extracted with $2 \times 5 \mathrm{~mL}$ of $n$-hexane. The hexane phase was discarded and the remaining aquous phase was acidified to $\mathrm{pH} 1$ by addition of $6 \mathrm{~N} \mathrm{HCl}$ solution, and extracted with $3 \times 10 \mathrm{~mL}$ of dichloromethane. The aqueous phase was removed and the dichloromethane extract was combined and dried by adding anhydrous $\mathrm{Na}_{2} \mathrm{SO}_{4}$. After being filtered through Whatmann filter paper, the extract was evaporated using a vacuum rotary evaporator at $40^{\circ} \mathrm{C}$ until solvent was completely removed ${ }^{17}$. The lipid extracts obtained were further determined using FTIR spectrometer.

\subsubsection{Bligh and Dyer Method}

Extraction of lipid fraction from lipstick formulation was carried out according to Constantinou et al. ${ }^{18)}$. About $4.0 \mathrm{~g}$ of lipstick sample in a screw-capped polypropylene centrifuge tube was mixed with $15 \mathrm{~mL}$ of chloroform-methanol

Table 1 The weight percentage ratios of lard and castor oil.

\begin{tabular}{cccccccccccc}
\hline Fat/oil & F.1 & F.2 & F.3 & F.4 & F.5 & F.6 & F.7 & F.8 & F.9 & F.10 & F.11 \\
\hline Lard & 0 & 10 & 20 & 30 & 40 & 50 & 60 & 70 & 80 & 90 & 100 \\
Castor oil & 100 & 90 & 80 & 70 & 60 & 50 & 40 & 30 & 20 & 10 & 0 \\
\hline
\end{tabular}

$\mathrm{F}=$ formula

For validation samples, nine lipstick samples of similar characteristic with calibration samples were constructed independently in our laboratory. 
(1:2), heated at about $60^{\circ} \mathrm{C}$ for 10 minutes, shaken vigorously for 1 minute, shaken by means of vortex mixer for 5 minutes, and centrifuged at 3,000 rpm for 10 minutes. The supernatant liquid was decanted into a separatory funnel. The residue in the tube was mixed with $5 \mathrm{~mL}$ of chloroform, shaken by means of vortex mixer for 5 minutes, and centrifuged at 3,000 rpm for 10 minutes. The supernatant liquid was decanted into a separatory funnel, after which 5 $\mathrm{mL}$ of distilled water was added and the mixture was shaken. Chloroform layer was drained and dried by adding anhydrous $\mathrm{Na}_{2} \mathrm{SO}_{4}$. After being filtered through Whatmann filter paper, the extract was evaporated using a vacuum rotary evaporator at $55^{\circ} \mathrm{C}$ until solvent was completely removed. The lipid extracts obtained were further determined using FTIR spectrophotometer.

2.2.5 FTIR spectra acquisition

The samples were scanned using an ABB MB3000 FTIR spectrometer (Clairet Scientific, Northampton, UK) equipped with a deuterated triglycine sulfate (DTGS) detector with a resolution of $8 \mathrm{~cm}^{-1}$, number of scans 32 , and wavenumber region of 4,000-650 $\mathrm{cm}^{-1}$. Spectra were acquired using Horizon MB FTIR software version 3.0.13.1 (ABB, Cannada). The samples were placed in contact with an attenuated total reflectance (ATR) element ( $\mathrm{ZnSe}$ crystal) at a controlled ambient temperature $\left(20^{\circ} \mathrm{C}\right)$. All spectra were ratioed against a background of an air spectrum. After every scan, a new reference air background spectrum was taken. These spectra were recorded as absorbance values at each data point in triplicate.

\subsubsection{Fatty Acids Analysis by Gas Chromatography}

Fat/oil extracts were first derivatized into the volatile fatty acid methyl esters (FAMEs) using $0.2 \mathrm{~N}$ solution of sodium methoxide and solution of boron trifluoride in methanol according to Rohman and Che $\operatorname{Man}^{19)}$. The FAMEs were then analyzed by a gas chromatograph equipped with a flame ionization detector. Fatty acid concentrations are calculated based on the area by internal normalization technique using the area obtained from the chromatogram of the sample.

2.2.7 Fatty acid Quantitation by Gas Chromatography

Fatty acid methyl esters were analyzed on an Agilent 7890B gas chromatograph (Agilent Technologies Inc., California, USA) equipped with an HP-5 (30 m ×0.32 mm i.d., $0.25 \mu \mathrm{m}$ film thickness) with helium as a carrier gas. Samples $(1 \mu \mathrm{L})$ were injected with a split ratio of 15:1 into the injector port, which was set at $260^{\circ} \mathrm{C}$. Initial oven temperature was $160^{\circ} \mathrm{C}$ with a 2 min holding, followed by a $10^{\circ} \mathrm{C} / \mathrm{min}$ ramp to $270^{\circ} \mathrm{C}$, with a $7 \mathrm{~min}$ holding at the end. The flame ionisation detector temperature was set at $260^{\circ} \mathrm{C}$ with air. The rates of hydrogen, helium and nitrogen make-up gas flow 400, 40, and $30 \mathrm{~mL} / \mathrm{min}$, respectively.

2.2.8 Fatty Acid Identity Confirmation by Gas Chromatography-Mass Spectrometry

Fatty acids methyl esters were also analyzed on a GCMS-
QP2010S gas chromatograph-mass spectrometer with a quadrupole ion trap in external electron ionisation mode (Shimadzu, Japan). The gas chromatograph was equipped with a DB-1 (30 m $\times 0.25 \mathrm{~mm}$ i.d., $25 \mu \mathrm{m}$ film thickness $)$ capillary column interfaced directly into the ion source with helium as carrier gas. Initial oven temperature was $50^{\circ} \mathrm{C}$ with a $5 \mathrm{~min}$ hold, followed by a $5^{\circ} \mathrm{C} / \mathrm{min}$ ramp to $260^{\circ} \mathrm{C}$ and a $13 \mathrm{~min}$ hold at the end. The injector was set at $300^{\circ} \mathrm{C}$, while the ion source was set at $250^{\circ} \mathrm{C}$. Electron impact ionization mode was used with electron energy of $70 \mathrm{eV}$. Mass range was set at $28-600 \mathrm{~m} / z$. Mass spectra were cross referenced with WILLEY/NIST Mass Spectral Library for identification and confirmation of fatty acids.

\subsubsection{Statistical Analysis}

Partial least square (PLS) calibration and principal component analysis (PCA) were performed using Horizon MB FTIR software version 3.1.24.2 (ABB, Canada). The leaveone-out cross-validation procedure was used to verify the calibration model. The values of the root mean square error of calibration (RMSEC) and coefficient of determination $\left(\mathrm{R}^{2}\right)$ were used as the validity criteria for the calibration model. PLS calibration model was further used to predict the levels of lard in validation samples. The values of the root mean square error of prediction (RMSEP) and coefficient of determination $\left(\mathrm{R}^{2}\right)$ were used as the validity criteria for the calibration model.

\section{Results and Discussion}

\subsection{Spectra Analysis}

Figure 1 shows FTIR spectra of LD and castor oil(CT) extracted from lipstick formulation using three extraction methods in the mid-infrared (MIR) region $\left(4,000-650 \mathrm{~cm}^{-1}\right)$. Generally, each band in the FTIR spectra corresponds to a functional group responsible for IR absorption ${ }^{20)}$. The peak assignment together with functional groups responsible for peak absorption in Fig. 1 is shown in Table 2. FTIR spectroscopic analysis revealed that the spectra of samples extracted by saponification I (SI) and saponification II (SII) methods showed a similar profile of fatty acid spectra characterized by a broad band at wavenumber region of 3400$2400 \mathrm{~cm}^{-1}$ (hydroxyl group of the carboxylic acids) and a sharp, intense band approximately at $1709 \mathrm{~cm}^{-1}$ (carbonyl group of the fatty acids). Meanwhile, the spectra of the samples obtained from Bligh \& Dyer extraction method showed the typical spectra of triglycerides characterized by the absence of the broad band at wavenumber of 3400$2400 \mathrm{~cm}^{-1}$ and the presence of a sharp, intense band near $1736 \mathrm{~cm}^{-1}$ (carbonyl group of esters). Saponification caused triglycerides to hydrolyze into fatty acids and glycerol.

All spectra showed bands of absorbance due to stretching vibration of $\mathrm{C}-\mathrm{H}$ cis-double bond at $3009 \mathrm{~cm}^{-1}$ (c) and 


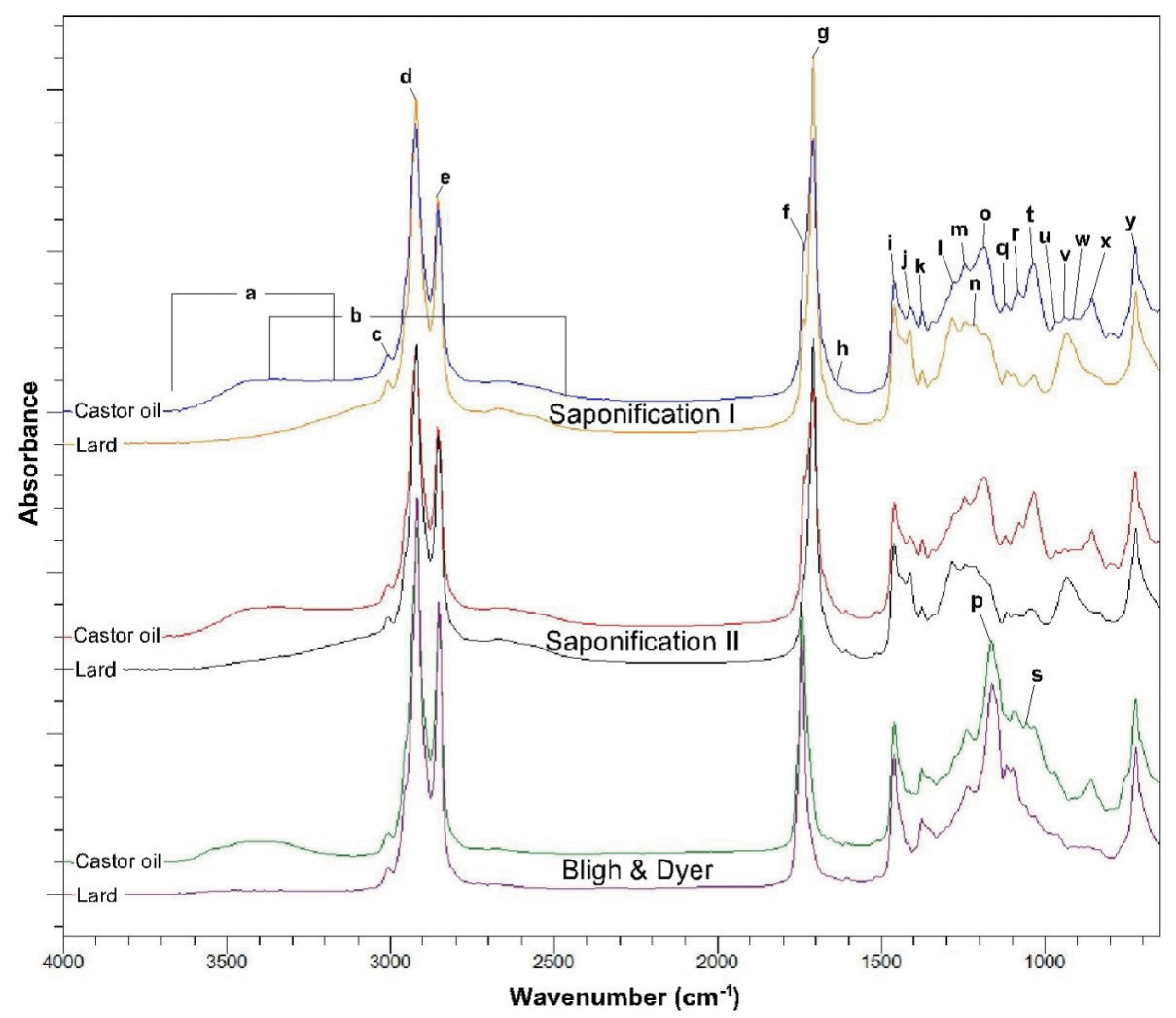

Fig. 1 The FTIR spectra of lard and castor oil extracted by three extraction methods from prepared lipstick formulation.

stretching vibration of methylene group symmetric at 2924 $\mathrm{cm}^{-1}(\mathrm{~d})$ and asymmetric at $2854 \mathrm{~cm}^{-1}(\mathrm{e})$. A band showing a stretching vibration of carbonyl group of ester can only be seen in samples extracted by SI and SII methods at 1734 $\mathrm{cm}^{-1}(\mathbf{f})$, while a band showing strecthing vibration of carboxylic acid (FFA) at $1709 \mathrm{~cm}^{-1}$ (pita g). In case of SI and SII, intensity of band at $1700 \mathrm{~cm}^{-1}$ was relatively higher in $\mathrm{LD}$ than that in CT. This is because castor oil is readily soluble in ethanol used as solvent for saponification reaction. In samples extracted by Bligh \& Dryer method, Stretching vibration of disubstitued cis-olefins shows a weak band at $1655 \mathrm{~cm}^{-1}(\mathrm{~h})$. In fingerprint region, methylene and methyl scissoring bending vibrations can be observed at $1465 \mathrm{~cm}^{-1}(\mathrm{i})$ in all samples. Absorbtion bands at $1416 \mathrm{~cm}^{-1}(\mathrm{j})$ and $1377 \mathrm{~cm}^{-1}(\mathrm{k})$ due to $\mathrm{C}-\mathrm{H}$ rocking vibration of disubstituted cis-olefin and symmetrical bending vibration of methyl group, respectively, are also observed in all samples. However, peak intensity at the latter wavelength is lower in samples with SI and SII than that in samples with Bligh \& Dryer method.

A group of band appearing in wavelength region of 1300$1000 \mathrm{~cm}^{-1}$ is due to C-O stretching vibration of esters, free fatty acids or alcohol. A band, I, at $1277 \mathrm{~cm}^{-1}$ due to C-O stretching vibration is present in spectra of samples with SAPH and SAPDH, but absent in that of samples with BD. A band at approximately $1238 \mathrm{~cm}^{-1}(\mathrm{~m})$ is due to an overlap of $\mathrm{C}-\mathrm{O}$ stretching and methylene out of plane vibration.
The C-O stretching vibration at $1219 \mathrm{~cm}^{-1}(\mathrm{n})$ can only be detected in LD with SAPH and SAPHD. This means that the latter band is caused by fatty acid that is only present in LD. A band, o, at $1184 \mathrm{~cm}^{-1}$ is observed in samples with $\mathrm{SAPH}$ and SAPHD, but not in those with BD. This band is due to $\mathrm{C}-\mathrm{O}$ stretching vibration of free fatty acid. The C-O stretching vibration of triglyceride ester causes a band at $1161 \mathrm{~cm}^{-1}(p)$. A pair of bands $\mathrm{q}$ and $\mathrm{r}$ at $1119 \mathrm{~cm}^{-1}$ and $1095 \mathrm{~cm}^{-1}$, respectively, is observed in all samples, but the intensity ratio of band $\mathbf{q}$ and band $r$ is obviously higher in CT than that in LD. Furthermore, in LD with BD extraction, this ratio is close to 1 . A band, s, at aproximately 1057 $\mathrm{cm}^{-1}$, observed only in samples with $\mathrm{BD}$, is due $\mathrm{C}-\mathrm{O}$ stretching vibration of triglyceride ester ${ }^{21-23)}$.

The out-of-plane bending vibration of disubstituted trans-olefins causes a weak absorption at $968 \mathrm{~cm}^{-1}(\mathbf{u})$ in all CT samples, while that of disubstituted cis-olefins causes a weak absorption at $941 \mathrm{~cm}^{-1}(\mathbf{v})$ in samples with SI and SII. Furthermore, similar mode of vibration of disubstituted cis-olefins causes a weak absorption at $914 \mathrm{~cm}^{-1}$ (pita w) in all CT samples and in $\mathrm{LD}$ with $\mathrm{BD}$ extraction. Clearly, a wagging vibration of $=\mathrm{CH}_{2}$ can only be observed in CT samples at $856 \mathrm{~cm}^{-1}(\mathbf{x})$. Finally, in all samples, a band at $721 \mathrm{~cm}^{-1}(\mathbf{y})$ results from the overlapping of the methylene rocking vibration and the out-of-plane bending vibration of cis-disubstituted olefins $^{21)}$. 
Table 2 Functional groups responsible for peak absorption in FTIR spectra of lard and castor oil extracted using three extraction methods from prepared lipstick formulation.

\begin{tabular}{|c|c|c|c|c|c|c|c|c|c|}
\hline \multirow[b]{2}{*}{ Band } & \multicolumn{7}{|c|}{ Wavelength $\left(\mathrm{cm}^{-1}\right)$} & \multirow{2}{*}{$\begin{array}{l}\text { Functional } \\
\text { Group }\end{array}$} & \multirow[b]{2}{*}{ Mode of Vibration } \\
\hline & LD1 & LD2 & LD3 & $\mathrm{CT} 1$ & $\mathrm{CT} 2$ & СT3 & $\begin{array}{c}\text { Ref } \\
{[17]-[19]}\end{array}$ & & \\
\hline $\mathrm{a}$ & - & - & - & $\begin{array}{l}3,650- \\
3,150\end{array}$ & $\begin{array}{l}3,650- \\
3,150\end{array}$ & $\begin{array}{l}3,650- \\
3,150\end{array}$ & $\begin{array}{l}3,650- \\
3,200\end{array}$ & -O-H (alcohol) & Stretching \\
\hline $\mathrm{b}$ & $\begin{array}{l}3,400- \\
2,400\end{array}$ & $\begin{array}{l}3,400- \\
2,400\end{array}$ & - & $\begin{array}{l}3,650- \\
2,400\end{array}$ & $\begin{array}{l}3,650- \\
2,400\end{array}$ & - & $\begin{array}{l}3,400- \\
2,400\end{array}$ & $-\mathrm{O}-\mathrm{H}$ (acid) & Stretching \\
\hline $\mathrm{c}$ & 3,009 & 3,009 & 3,005 & 3,009 & 3,009 & 3,009 & 3,006 & $=\mathrm{C}-\mathrm{H}(c i s-)$ & Stretching \\
\hline d & 2,924 & 2,920 & 2,920 & 2,924 & 2,924 & 2,920 & 2,924 & $-\mathrm{C}-\mathrm{H}\left(\mathrm{CH}_{2}\right)$ & $\begin{array}{c}\text { Stretching } \\
\text { (asymmetrical) }\end{array}$ \\
\hline $\mathrm{e}$ & 2,854 & 2,854 & 2,851 & 2,854 & 2,854 & 2,851 & 2,853 & $-\mathrm{C}-\mathrm{H}\left(\mathrm{CH}_{2}\right)$ & Stretching (symmetrical) \\
\hline $\mathrm{f}$ & 1,736 & 1,736 & 1,744 & 1,736 & 1,736 & 1,744 & 1,746 & $-\mathrm{C}=\mathrm{O}$ (ester) & Stretching \\
\hline $\mathrm{g}$ & 1,709 & 1,709 & - & 1,709 & 1,709 & - & 1,711 & $-\mathrm{C}=\mathrm{O}(\mathrm{CA})$ & Stretching \\
\hline $\mathrm{h}$ & - & - & 1655 & - & - & 1,659 & 1,654 & $-\mathrm{C}=\mathrm{C}-($ cis -$)$ & Stretching \\
\hline $\mathrm{i}$ & 1,462 & 1,462 & 1,462 & 1,462 & 1,462 & 1,462 & 1,465 & $-\mathrm{C}-\mathrm{H}\left(\mathrm{CH}_{2}, \mathrm{CH}_{3}\right)$ & Bending (scissoring) \\
\hline $\mathrm{j}$ & 1,412 & 1,412 & 1,419 & 1,412 & 1,412 & 1,416 & 1,418 & $=\mathrm{C}-\mathrm{H}(c i s-)$ & Bending (rocking) \\
\hline $\mathrm{k}$ & 1,377 & 1,377 & 1,377 & 1,373 & 1,373 & 1,377 & 1,377 & $-\mathrm{C}-\mathrm{H}\left(\mathrm{CH}_{3}\right)$ & Bending (symmetrical) \\
\hline 1 & 1,281 & 1,281 & - & 1,277 & 1277 & - & - & $-\mathrm{C}-\mathrm{O}(\mathrm{CA})$ & Stretching \\
\hline $\mathrm{m}$ & 1,242 & 1,242 & 1,234 & 1,242 & 1246 & 1,238 & 1,238 & $\begin{array}{l}\text {-C-O (ester, CA), } \\
\text {-C-H }\left(\mathrm{CH}_{2}\right)\end{array}$ & $\begin{array}{c}\text { Stretching, } \\
\text { Bending (out of plane) }\end{array}$ \\
\hline $\mathrm{n}$ & 1,219 & 1,219 & - & - & - & - & - & $-\mathrm{C}-\mathrm{O}(\mathrm{CA})$ & Stretching \\
\hline o & 1,184 & 1,184 & - & 1,188 & 1184 & - & - & $-\mathrm{C}-\mathrm{O}(\mathrm{CA})$ & Stretching \\
\hline $\mathrm{p}$ & - & - & 1,161 & - & - & 1,161 & 1,163 & -C-O (ester, CA) & Stretching \\
\hline $\mathrm{q}$ & 1,115 & 1,119 & 1,115 & 1,119 & 1119 & 1,119 & 1,118 & -C-O (ester, CA) & Stretching \\
\hline $\mathrm{r}$ & 1,095 & 1,092 & 1,095 & 1,080 & 1080 & 1,095 & 1,097 & -C-O (ester, CA) & Stretching \\
\hline $\mathrm{s}$ & - & 1,049 & 1,061 & - & - & 1,057 & - & -C-O (ester) & Stretching \\
\hline $\mathrm{t}$ & 1,034 & 1,038 & 1,034 & 1,034 & 1034 & 1,034 & 1,033 & -C-O (ester, CA) & Stretching \\
\hline $\mathrm{u}$ & - & - & - & 964 & 964 & 968 & 968 & $=\mathrm{C}-\mathrm{H}($ trans -$)$ & Bending (out of plane) \\
\hline $\mathrm{v}$ & 933 & 933 & - & 941 & 941 & - & - & $=\mathrm{C}-\mathrm{H}($ cis- $)$ & Bending (out of plane) \\
\hline $\mathrm{w}$ & - & - & 914 & 914 & 914 & 910 & 914 & $=\mathrm{C}-\mathrm{H}(c i s-)$ & Bending (out of plane) \\
\hline $\mathrm{x}$ & - & - & - & 856 & 856 & 860 & 848 & $=\mathrm{CH}_{2}$ & Bending (wagging) \\
\hline $\mathrm{y}$ & 721 & 721 & 721 & 721 & 725 & 721 & 721 & $\begin{aligned} & -\left(\mathrm{CH}_{2}\right)_{n}- \\
= & \mathrm{C}-\mathrm{H}(\text { cis- })\end{aligned}$ & $\begin{array}{l}\text { Bending (rocking), } \\
\text { Bending (out of plane) }\end{array}$ \\
\hline
\end{tabular}

$\mathrm{LD}=\mathrm{Lard} ; \mathrm{CT}=$ Castor oil $; \mathrm{CA}=$ carboxylic acid

\subsection{Classification of Lipsticks Containing Lard}

Classification of lipsticks with and without LD in their formulation was performed using principal component analysis (PCA). PCA is one of the unsupervised pattern recognition techniques used in multivariate analysis. PCA projects the original data in reduced dimensions defined by the principal components $(\mathrm{PC})$. This technique is useful when there is a correlation among data. In this study, PCA was accomplished using FTIR spectra absorbances of lipsticks containing $\mathrm{LD}$ and castor oil at wavenumber region of 1,200-800 $\mathrm{cm}^{-1}$. Selection of wavenumbers used for analysis was based on its ability to produce a score plot showing no or minimal misclassification of lard and castor oil data. Figure 2 revealed score plots of score plot of LD and castor oil extracted by three extraction methods (saponification method I, saponification method II, and Bligh and Dyer) from lipstick formulation. The first principle component(PC1) accounted for $63.7 \%$ of the variation, while the second principle component (PC2) described $26.4 \%$ of the variation; therefore, $90.1 \%$ of the variance is 


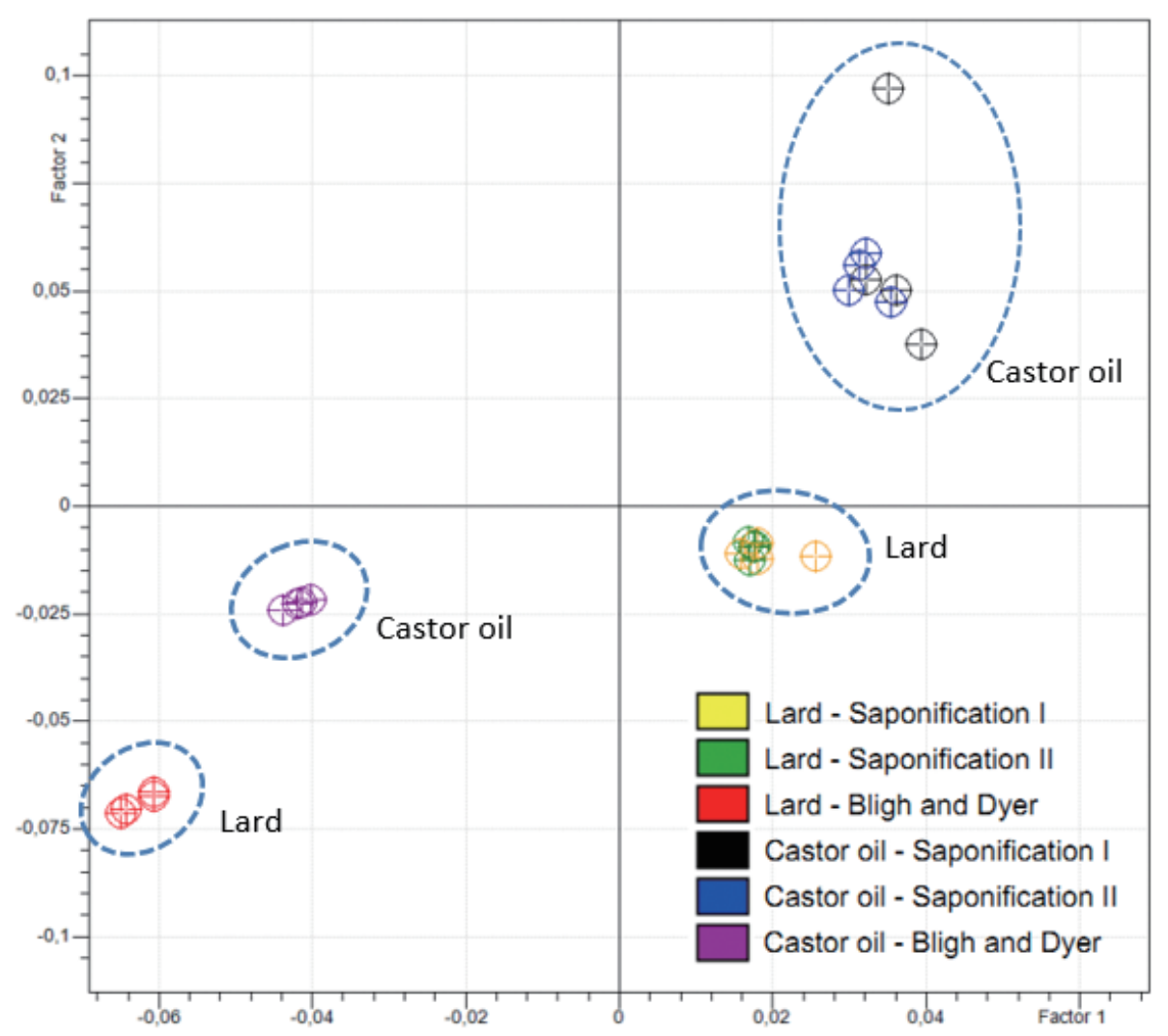

Fig. 2 Score plot of lard and castor oil extracted by three extraction methods (saponification method I, saponification method II, and Bligh and Dyer) from lipstick formulation.

being described by the first two PCs. Base on PC1 and PC2, LD and castor oil can be classified successfully.

To differentiate the score plot of each extraction techniques, Figure 3 demonstrate score plots of LD and castor oil extracted from lipstick formulation by saponification method I, saponification method II, and Bligh \& Dyer method, respectively, representing the projection of samples defined by PC1 and PC2. Based on the projection, plots of $\mathrm{LD}$ and castor oil are well separated meaning that PCA can accomplish the classification between lipstick containing LD and castor oil using separate three extraction techniques.

\subsection{Quantification of Lard in Lipsticks}

Quantification of LD in a mixture with castor oil as the oil base in lipstics was performed using multivariate calibration of PLS at the combined frequency region of 1,200$800 \mathrm{~cm}^{-1}$. This region was chosen due to its ability to offer the higher value of $\mathrm{R}^{2}$ and the lower value of RMSEC. The main advantage of PLS is due to its ability to develop the correlation between FTIR spectra and an analyte of interest, even when no differences are visually observable in FTIR spectral data.

Quantitative analysis of lard and castor oil in lipstick formulation was accomplished by PLS calibration. The number of factors used in the PLS calibration model was determined based on the number of factors at which predicted residual error sum of squares (PRESS) reaches a minimum. The PRESS Value is calculated as:

$$
\text { PRESS }=\sqrt{\frac{\sum_{i=1}^{n}(\text { actual }- \text { calculated })^{2}}{N-f-1}}
$$

The term "actual" refers to the known or true concentration of selected standards. Meanwhile the "calculated" is value calculated by PLS model during PLS modelling; where $\mathrm{N}$ is the number of standards used; and $\mathrm{f}$ is number of factors used in the calibration model. the lower the PRESS, the better the model predictive ability ${ }^{24)}$.

Figure 4 shows the scatter plot for relationship between actual value versus FTIR predicted value of lard extracted by the three extraction methods used at wavenumber region of 1,200-800 $\mathrm{cm}^{-1}$. Quantification of lard in lipstick formulation extracted by Bligh \& Dyer method using multivariate PLS calibration showed the best results. PLS is capable of predicting the amount of lard in lipstick formulation with the equation $\mathrm{y}=1.0070 \mathrm{x}-0.4563\left(\mathrm{R}^{2}=0.9956\right)$ for the calibration equation and $y=0.9811 x+0.3381\left(R^{2}=\right.$ 0.9970 ) for the validation equation. Figure 5 show overlayed FTIR spectra of lard, castor oil, and their blends extracted from prepared lipstick formulations by Bligh \& Dyer, respectively. 
A

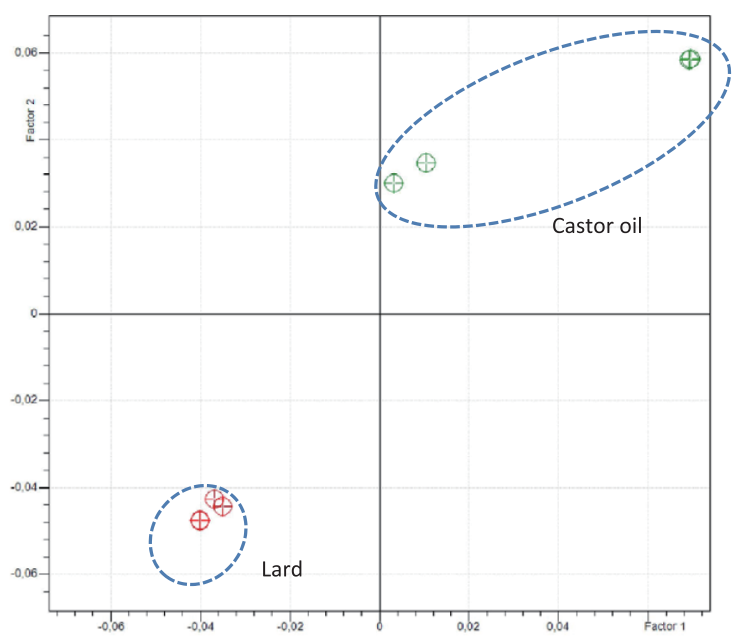

B

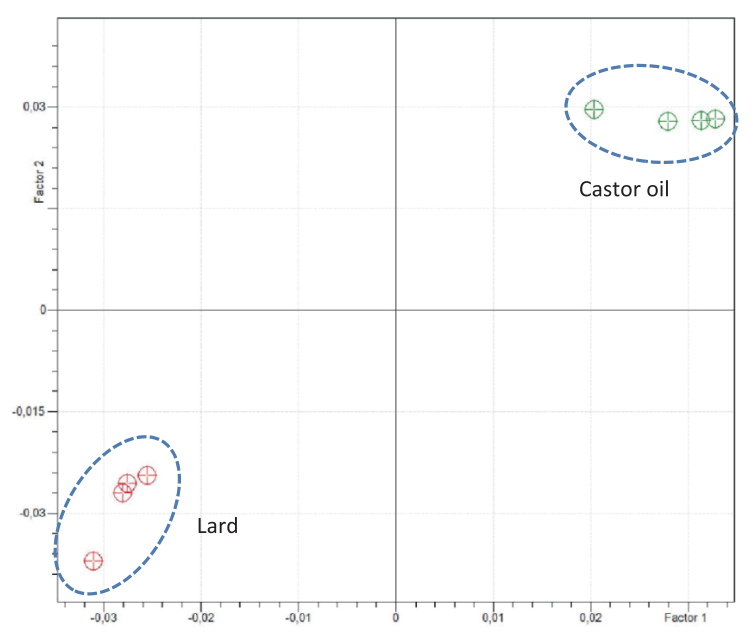

C

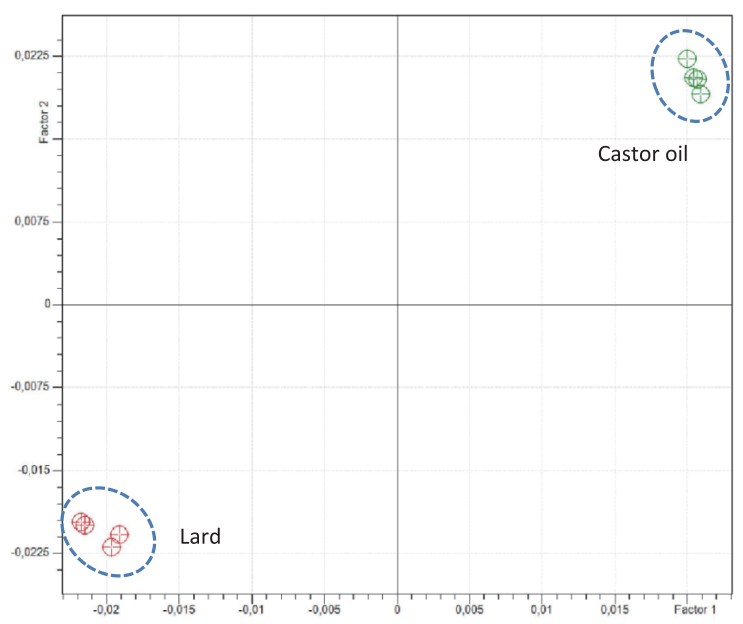

Fig. 3 Score plot of lard and castor oil extracted by saponification method I(A), saponification method II(B) and by Bligh \& Dyer method (C) from lipstick formulation.
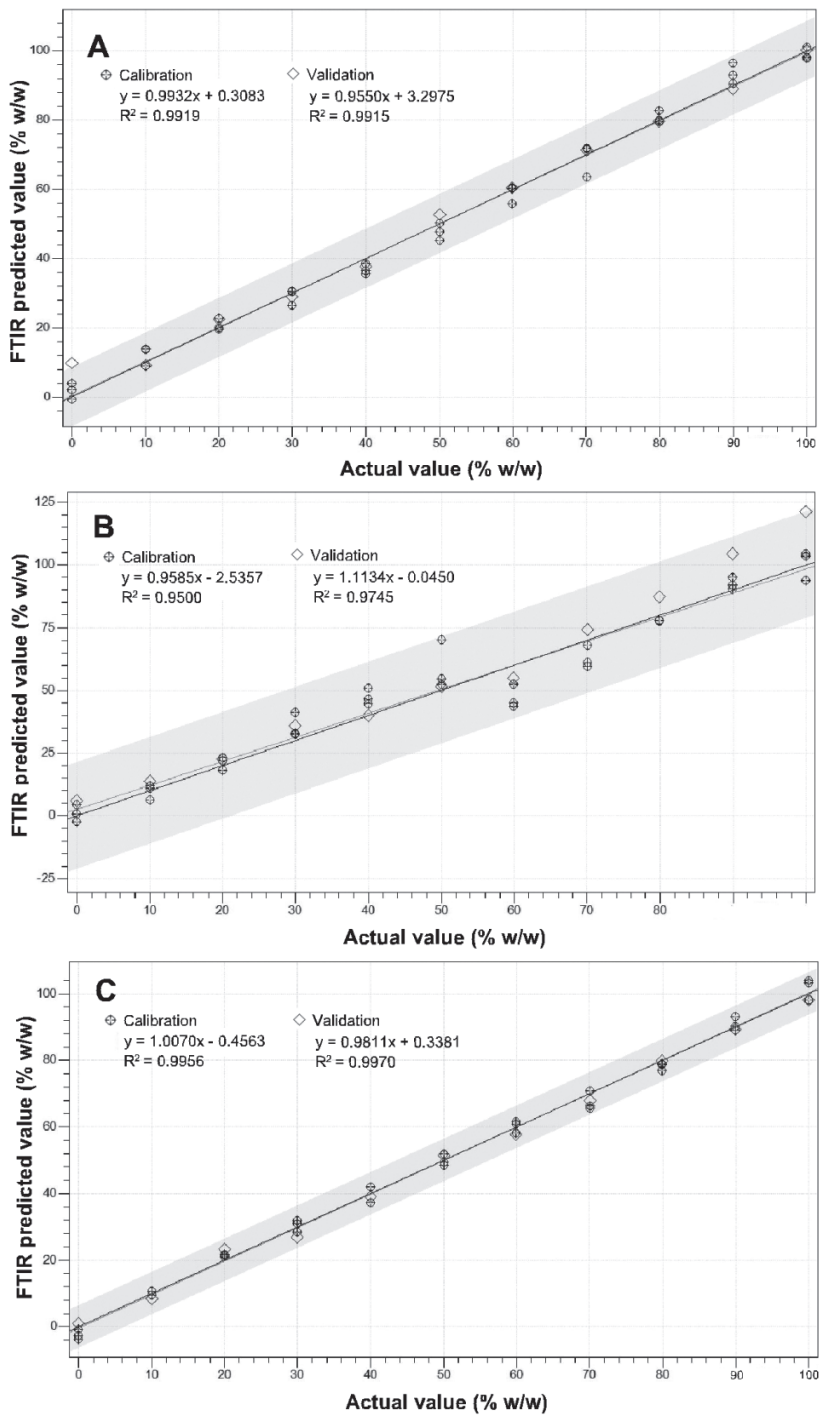

Fig. 4 The scatter plot for relationship between actual value versus FTIR predicted value of lard extracted by saponification method I from prepared lipstick formulations $(\% \mathrm{v} / \mathrm{v})$ using PLS calibration at wavelength regions of $1,200-800 \mathrm{~cm}^{-1} . \mathrm{A}=$ saponification I; $\mathrm{B}=$ saponification II; $\mathrm{C}=\mathrm{Bligh} \&$ Dyer.

\subsection{Analysis of Commercial Lipsticks}

The developed method was further used for analysis of lipstick preparations commercially available in some supermarkets in Yogyakarta. According to the results of qualitative and quantitative analysis of LD using calibration and validation samples, Bligh \& Dyer method was chosen to extract fat/oil from the unknown lipstick samples suspected of containing both $\mathrm{LD}$ and castor oil. The decision was made according to the proximity of unknown samples with respect to $\mathrm{LD}$ and castor oil. The closer the distance, the higher the possibilities of unknown samples falling into one of the two groups. The score plot of commercial lipstick 


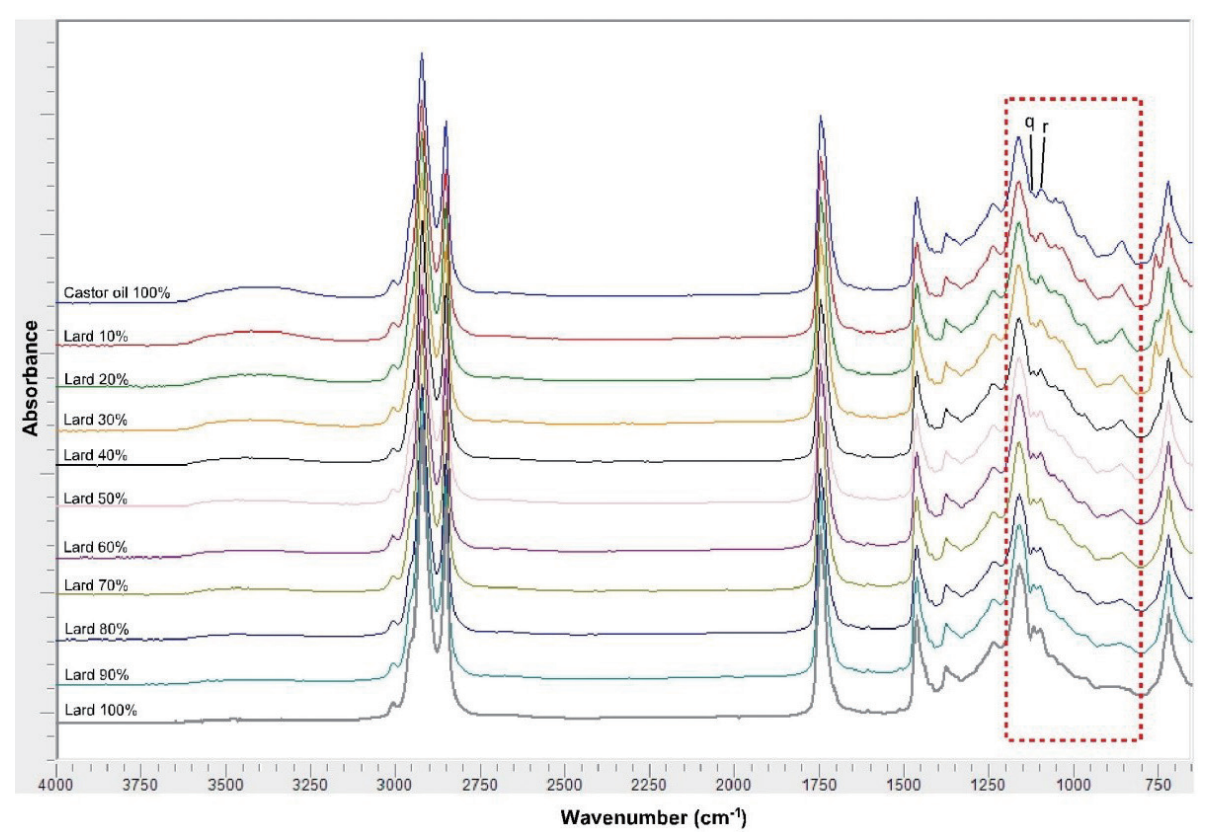

Fig. 5 Overlayed FTIR spectra of lard, castor oil, and their blends extracted by Bligh \& Dyer method from prepared lipstick formulations.

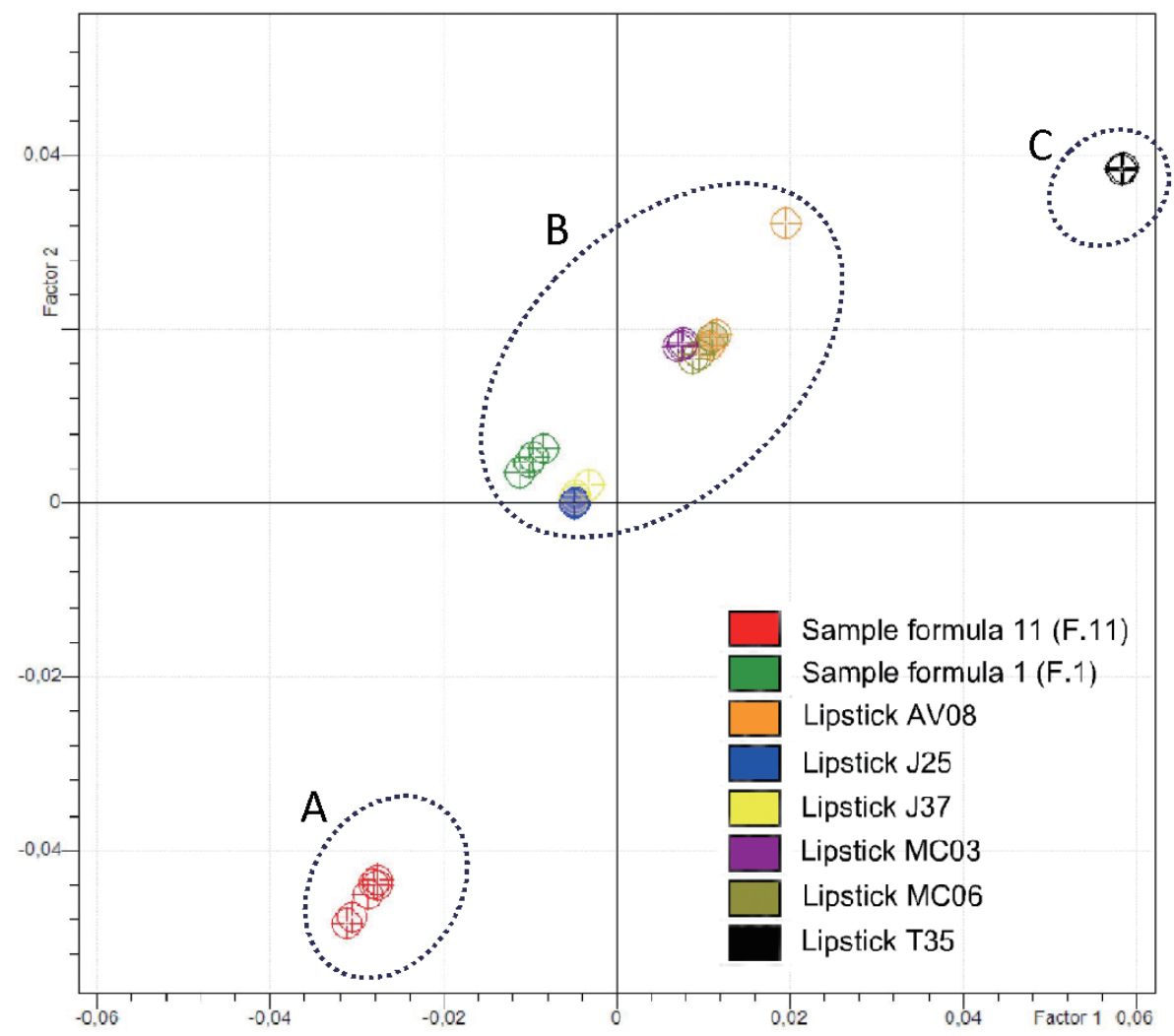

Fig. 6 Score plot of lard and castor oil extracted by Bligh \& Dyer method from commercial lipsticks.

samples is shown in Fig. 6. From this figure, it can be seen that at wavenumber region of $1,200-800 \mathrm{~cm}^{-1}$ there are no commercial lipstick samples falling close to LD lipsticks. However, one lipstick sample, namely T35, fell not so close to castor oil lipsticks meaning that it contains both castor oil and other oil (other than LD). 
Table 3 Fatty acid composition of lard and castor oil extracted using three extraction methods from prepared lipstick formulation.

\begin{tabular}{lcccccccc}
\hline & \multicolumn{1}{c}{ Fatty acid concentration (\%) } \\
\cline { 2 - 8 } & LD1 & LD2 & LD3 & CT1 & CT2 & CT3 & P (significant value)* \\
\hline Caproic (C6:0) & nd & nd & nd & nd & nd & nd & - \\
Caprylic (C8:0) & $<0.1$ & $<0.1$ & $<0.1$ & $<0.1$ & $<0.1$ & $<0.1$ & - \\
Capric (C10:0) & $<0.1$ & $<0.1$ & $<0.1$ & $<0.1$ & $<0.1$ & $<0.1$ & - \\
Lauric (C12:0) & 0.46 & 0.71 & 0.72 & $<0.1$ & 0.14 & 0.20 & 0.006 (significant) \\
Myristic (C14:0) & 1.92 & 2.26 & 1.67 & 0.10 & $<0.1$ & 0.10 & 0.000 (significant) \\
Palmitoleic (C16:1) & 1.05 & 2.15 & 3.80 & $<0.1$ & nd & nd & 0.000 (significant) \\
Palmitic (C16:0) & 24.87 & 25.60 & 23.09 & 4.69 & 3.67 & 5.12 & 0.000 (significant) \\
Heptadecanoic (C17:0) & 0.24 & 0.22 & 0.27 & $<0.1$ & $<0.1$ & $<0.1$ & 0.000 (significant) \\
Linoleic (C18:2n6) & nd & nd & nd & 3.61 & 3.17 & 3.79 & 0.000 (significant) \\
$\alpha$-Linolenic (C18:3n3) and/or & 26.43 & 26.40 & 22.72 & 3.56 & 2.41 & 2.96 & 0.000 (significant) \\
$\gamma$-Linolenic (C18:3n6) and/or Oleic (C18:1n9) & & & & & & & \\
Stearic (C18:0) & 10.01 & 9.30 & 10.88 & 3.22 & 2.66 & 3.49 & 0.001 (significant) \\
Risinoleic (C18:1-12OH) & nd & nd & nd & 83.35 & 86.62 & 83.65 & 0.000 (significant) \\
Behenic (C22:0) & $<0.1$ & $<0.1$ & $<0.1$ & $<0.1$ & $<0.1$ & $<0.1$ & - \\
Lignoseric (C24:0) & 0.23 & 0.69 & 1.09 & 0.24 & 0.16 & 0.24 & 0.142 (not significant different) \\
Saturated fatty acid & 37.73 & 38.78 & 37.72 & 8.33 & 6.73 & 9.20 & 0.000 (significant) \\
Unsaturated fatty acid & 27.48 & 28.55 & 26.52 & 90.54 & 92.2 & 90.4 & 0.000 (significant) \\
\hline
\end{tabular}

LD1, LD2, and LD1 = fat/oil extracted from lipstick containing lard using extraction methods of saponification I, saponification II, and Bligh \& Dyer, respectively; CT1, CT2, and CT2 = fat/oil extracted from lipstick containing castor oil using extraction methods of saponification I, saponification II, and Bligh \& Dyer, respectively; nd = not detected; ${ }^{*}$ based on independent t-test performed using SPSS software version 22. $\mathrm{P}$ value $<0.05$ is statistically different.

\subsection{Analysis of Fatty Acid Composition by Gas Chroma- tography}

Fatty acid composition of lard and castor oil extracted by three extraction methods from prepared lipstick formulation was analyzed using GC with flame ionization detection and confirmed using GC-MS. As shown in Table 3, the three different extraction methods gave similiar fatty acid composition. The main fatty acid content of fat/oil extracted from prepared lipstick formulation containing $\mathrm{LD}$ is palmitic acid (23-26\%), while that from prepared lipstick formulation containing castor oil is ricinoleic acid (83-87\%). Furthermore, extracts of LD lipstick contain more saturated fatty acids (37-38\%) than those of castor oil lipstick (8-9\%). The fatty acids composition of LD and castor oil was subjected to significance test using independent sample t-test at significance level of 0.05 . The level of lignoseric acid in LD and castor oil is not statistically different, while caproic, caprylic and capric acids are not subjected to statistical test because its levels are not detected or $<0.1 \%$. Using this technique, oil with levels of $0.001 \mathrm{~g}$ fat/g sample in any products containing lard and castor oil could be detected ${ }^{25)}$.

\section{Conclusions}

It can be concluded that FTIR spectroscopy combined with multivariate analysis of principal component analysis and partial least squares can be used to analyze the presence of LD in lipstick formulation. Amonf three extraction methods, Bligh \& Dryer is more preferred for classification and quantification of lard in cosmetics samples. The wavenumber region used is $1,200-800 \mathrm{~cm}^{-1}$. The results can be extended to various types of topical cosmetic preparations using oils as a base in their formulation.

\section{Acknowledgement}

This research was financially supported by a grant from the Director General of Higher Education, Ministry of Education and Culture, through the project number of LPPMUGM/346/LIT/2014.

\section{References}

1) Ogilvie, M.; Ryan, M. Lipstick: More than a Fashion Trend. Res. J. Soc. Sci. Manag. 1, 117-128(2011).

2) Anonymous. Final report on the safety assessment of 
lard glyceride, hydrogenated lard glyceride, lard glycerides, hydrogenated lard glycerides, lard and hydrogenated lard. Int. J. Toxicol. 20 Suppl. 2, 57-64 (2001).

3) Regenstein, J. M.; Chaudry, M. M.; Regenstein, C.E. The kosher and halal food laws. Compr. Rev. Food Sci. Food Saf. 2, 111-127 (2003).

4) Food and Drug Administration. GRAS Substances (SCOGS) Database - Select Committee on GRAS Substances (SCOGS) Opinion: Lard (packaging), Retrieved on $23^{\text {rd }}$ November 2014 from http://www.fda.gov/Food/ IngredientsPackagingLabeling/ GRAS/SCOGS/ ucm260450.htm, (2013).

5) Lauffer, P. G. I. Lipsticks. In: Cosmetics: Science and Technology, John Wiley \& Sons, Canada, pp. 365-377 (1972).

6) Che Man, Y. B.; Syahariza, Z. A.; Mirghani, M. E. S.; Jinap, S.; Bakar, J. Analysis of potential lard adulteration in chocolate and chocolate products using Fourier transform infrared spectroscopy. Food Chem. 90, 815819 (2005).

7) Nurrulhidayah, A. F.; Rohman, A.; Amin, I.; Shuhaimi, M.; Khatib, A. Analysis of chicken fat as adulterant in butter using fourier transform infrared spectroscopy and chemometrics. Grasas y Aceites 64, 349-355 (2013).

8) Rohman, A.; Gupitasari, I.; Purwanto; Triyana, K.; Rosman, A. S.; Ahmad, S. A. S.; Yusof, F. M. Quantification of lard in the mixture with olive oil in cream cosmetics based on FTIR spectra and chemometrics for Halal authentication. Jurnal Teknologi 69, 113-119(2014).

9) Marikkar, J. M. N.; Lai, O. M.; Ghazali, H. M.; Che Man, Y. B. Compositional and thermal analysis of RBD palm oil adulterated with lipase-catalyzed interesterified lard. Food Chem. 76, 249-258(2002).

10) Rohman, A.; Triyana, K.; Sismindari; Erwanto, Y. Differentiation of lard and other animal fats based on triacylglycerols composition and principal component analysis. Int. Food Res. J. 19, 475-479 (2012).

11) Che Man, Y. B.; Gan, H. L.; NorAini, I.; Nazimah, S. A. H.; Tan, C. P. Detection of lard adulteration in RBD palm olein using an electronic nose. Food Chem. 90, 829-835 (2005).

12) Mansor, T. S. T.; Che Man, Y. B.; Rohman, A. Application of Fast Chromatography and Fourier transform infrared spectroscopy for analysis of lard adulteration in virgin coconut oil. Food Anal. Methods 4, 365-372 (2011).

13) Blanco, M.; Alcalá, M.; Planells, J.; Mulero, M. Quality control of cosmetic mixtures by NIR spectroscopy. Anal. Bioanal. Chem. 389, 1577-1583(2007).

14) Rohman, A.; Che Man, Y. B.; Sismindari. Quantitative analysis of virgin coconut oil in cream cosmetics preparations using fourier transform infrared (FTIR) spectroscopy. Pak. J. Pharm. Sci. 22, 415-420 (2009).

15) Lukitaningsih, E.; Sa'adah, M.; Purwanto, Rohman, A. Quantitative Analysis of lard in cosmetic lotion formulation using FTIR spectroscopy and partial least square calibration. J. Am. Oil Chem. Soc. 89, 15371543(2012).

16) Salimon, J.; Abdullah, B. M.; Salih, N. Saponification of Jatropha curcas seed oil: Optimization by D-optimal design. Int. J. Chem. Eng. 2012, 1-6(2012).

17) Pérez-Palacios, T.; Ruiz, J.; Martín, D.; Muriel, E.; Antequera, T. Comparison of different methods for total lipid quantification in meat and meat products. Food Chem. 110, 1025-1029 (2008).

18) Constantinou, M.; Georgiou, C.; Kapnissi-Christodoulou, C. Development of a reliable analytical protocol for the isolation of cholesterol oxidation products-a comparison of different lipid extraction and saponification methods. Food Anal. Methods. 8, 1499-1507 (2015).

19) Rohman, A.; Che Man, Y. B. The optimization of FTIR spectroscopy combined with partial least square for analysis of animal fats in quartenary mixtures. Spectroscopy 25, 169-176 (2011).

20) Rohman, A.; Che Man, Y. B.; Hashim, P.; Ismail, A. FTIR spectroscopy combined with chemometrics for analysis of lard adulteration in some vegetable oils. CyTA J. Food 9, 96-101(2011).

21) Guillén, M. D.; Cabo, N. Characterization of edible oils and lard by Fourier transform infrared spectroscopy. Relationships between composition and frequency of concrete bands in the fingerprint region. J. Am. Oil Chem. Soc. 74, 1281-1286 (1997).

22) Pavia, D. L.; Lampman, G. M.; Kriz, G. S.; Vyvyan, J. R. Infrared Spectroscopy. In: Introduction to spectroscopy: A guide for students of organic chemistry, $4^{\text {th }}$ edn. Cengage Learning, Washington, pp. 15-104 (2009).

23) Vlachos, N.; Skopelitis, Y.; Psaroudaki. M.; Konstantinidou, V.; Chatzilazarou, A.; Tegou, E. Applications of Fourier transform-infrared spectroscopy to edible oils. Anal. Chim. Acta 573-574, 459-465 (2006).

24) Paradkar, M. M.; Irudayaraj, J. A rapid FTIR spectroscopic method for estimation of caffeine in soft drinks and total methylxanthines in tea and coffee. J. Food Sci. 657, 2507-2511 (2002).

25) Godswill, N. N.; Frank, N. E. G.; Edson, M. Y. J. et al. GC-FID Method Development and validation parameters for analysis of palm oil (Elaeis guineensis Jacq.) fatty acids composition. Res. Plant Sci. 2, 53-66 (2014). 